\title{
Beyond Management and Sustainability: Visitor Experiences of Physical Accessibility in the Great Smoky Mountains National Park, USA
}

\author{
Rachel J. C. Chen ${ }^{1}$ \\ ${ }^{1}$ Center for Sustainable Business and Tourism, University of Tennessee, Knoxville, USA \\ Correspondence: Rachel J. C. Chen, Center for Sustainable Business and Tourism, University of Tennessee, 311 \\ Conference Center Building, Knoxville, TN 37996-413, USA. Tel: 1-865-974-0505. E-mail: rchen@utk.edu
}

Received: December 26, 2012 Accepted: January 28, 2013 Online Published: March 20, 2013

doi:10.5539/jms.v3n2p145 URL: http://dx.doi.org/10.5539/jms.v3n2p145

\begin{abstract}
The National Center on Accessibility sponsored this study to identify the perceptions and attitudes of people with physical disabilities toward their experiences related to physical accessibility in the Great Smoky Mountains National Park. A total of 300 questionnaires were distributed to individuals with disabilities onsite. Of these questionnaires, 122 completed and usable questionnaires were collected. The physical accessibility problems in the park identified by visitors with physical disabilities were lack of the width of doorways in restrooms, followed by lack of accessible trails, lack of grab bars in restrooms, and lack of curb cuts. The uniqueness of this project is that it represents the first time focusing on the perceptions and expectations of visitors with physical disabilities regarding the accessibility in an individual national park. In order to further understand accessibility in the US National Park Service, future research may consider collecting these patterns and attitudes from people with and without different disabilities (such as physical disabilities, hearing impairment, visual impairment) at various national park units (national parks, national historical sites, national parkways, and national monuments) at the state, regional, and national levels.
\end{abstract}

Keywords: visitors with disabilities, national park, accessibility

\section{Introduction}

Because of aging, chronic diseases, injuries, accidents, and other causes, the World Health Organization (2011) estimated that there are more than 650 million individuals with disabilities globally, and the population is increasing. Many studies (Burnett \& Baker, 2001; Jo et al., 2004; Turco, Stumbo, \& Garncarz, 1998) have noted the increasing number of people with disabilities as well as the economic importance of this population in the travel and tourism industry (Chou \& Chao, 2007; Eichhorn et al., 2008; Gröschl, 2007; Huh \& Singh, 2007; Israeli, 2002; Poria, Reichel, and Brandt, 2010; Shaw, 2007; Shaw \& Coles, 2004; Yates, 2007). The Americans with Disabilities Act of 1990 (ADA, 1990) defined individuals with disabilities as "those individuals with physical or mental impairments that substantially limit one or more of the major activities of life, such as walking, talking, caring for oneself, or working. " Many governments (including those in North America, parts of Europe, Australia, and New Zealand) have considered offering a barrier-free tourism environment to the senior population and individuals with disabilities (Abeyratne, 1995; Burnett \& Baker, 2001; Chen, 2002).

There is limited literature on the subject of disability tourism; however, it is common knowledge that there are barriers that this group must overcome to travel. This study lists numerous accessibility issues in the United States' Great Smoky Mountains National Park, as identified by visitors with disabilities.

\section{Literature Reviews}

\subsection{Terms of Disability}

Disability is a very broad word that can encompass a large number of people or can be very subjective to physical impairments. Burnett and Baker (2001) defined disability as "an individual with a physical impairment that limits activities." Studies have usually identified such limitations based on a person's ability to interact with their environment (Nicolle \& Peters 1999). According to the US Department of Commerce (2011), an individual with disabilities is defined as "when he/she has difficulty with...normal body functions[,] activities of daily living 
(ADLs) [,] certain expected roles[, or] performing usual activities." According to the World Health Organization (2011), the term disability is "an umbrella term, covering impairments, activity limitations, and participation restrictions. Impairment is a problem in body function or structure; an activity limitation is a difficulty encountered by an individual in executing a task or action; while a participation restriction is a problem experienced by an individual in involvement in life situations. Thus disability is a complex phenomenon, reflecting an interaction between features of a person's body and features of the society in which he or she lives. "Because of the increase in awareness of disabilities, human rights, and accessibility issues, several studies have adopted the WHO’s disability terminology (Daruwalla \& Darcy, 2005; Shaw \& Coles, 2004; Yates, 2007).

\subsection{The Facts of People with Disabilities}

In the US, there are approximately 54 million individuals with mild to severe disabilities, while 42 percent of people over 65 have disabilities (US Department of Commerce, 2011). People with disabilities are a growing niche in the tourism industry and are estimated to be worth approximately 117 billion USD. Disability tourism is gaining academic and government attention in Europe, America, and Asia (Bizjak, Knezevic, \& Cvetresnik, 2011). Marketers are realizing that people with disabilities are an increasingly large population with money to spend on travel (Ray and Ryder, 2003). Though Yates (2007) reported that "disabled travelers remain shadowy figures in the literature and their voices are rarely heard" (p. 153), understanding the experiences and perceptions of individuals with disabilities in tourism (Shaw, Veitch, \& Coles, 2005), travel (Park, 2007), retail (Baker, Stephens, $\&$ Hill, 2002), and parks and recreation activities (Chen, 2002) have recently drawn more attention.

Most previous studies of individuals with disabilities were conducted by interviewing professionals who work in the field rather than directly interviewing individuals with disabilities (Yates, 2007). The tourism and hospitality market in the U.S. is highly competitive, forcing marketers to specify niche targets. A 2003 study contended that "people with disabilities and their families would be able to spend at least \$27 billion per year" if certain accommodations would meet their needs (Travel Daily News, 2003). Such accommodations would affect millions of families. Analyzing how these needs can be met to increase disability tourism is the main objective for marketers who are looking for a boost in the competition.

Past studies have found that people with disabilities do not travel as much because of the lack of accessibility or their dissatisfaction with assistance (Brodia \& Germann, 1999; Penniston, 1996; Turco et al., 1998). Most researchers reported that travel service personnel do not show specific sensitivity to the needs of persons with disabilities. Many marketers and their employees have not viewed tourists with disabilities as part of their market, despite the number of times these tourists have visited. Numerous studies have indicated that these tourists and their families were served because of the ADA. Studies have shown that individuals are beginning to view people with disabilities not as misfortunate people, but as individuals themselves. Awareness of this sector in the travel market is important so that appropriate emphasis is placed on changing service providers' attitudes toward visitors with disabilities.

\subsection{Attitudes toward Visitors with Disabilities}

Social knowledge, or attitudes, are developed from experiences, beliefs, and feelings. Attitudes are defined as the evaluations of people, objects, and ideas (Fazio \& Petty, 2008; Fishbein, 2008; Zanna \& Rempel, 2008). These attitudes can consist of an individual's positive or negative reactions to something. Dealing with attitudes towards people with disabilities involves two components: personal and societal. Personal components include beliefs and opinions held by an individual. Societal components are prevailing beliefs influenced by government, culture, background, or other conditions. For example, visitor centers are affected by societal attitudes because they have to follow government legislation for regulations of facilities.

Attitudes can be formed on our own consideration or evaluation of beliefs. Attitudes formed based on their own reasoning regarding how they associate themselves with an object. For instance, a visitor center's receptionist who believes that people with disabilities do not travel could form a negatively biased opinion about visitors with disabilities, affecting visitors' experience in the visitor center. Attitudes originate from numerous places, but can be narrowed down to people's values, sensory reactions, or aesthetic reactions (Aronson et al., 1998). Attitudes do and can change. If the employees are exposed to a controlled form of contact with people with disabilities, then there can be more efficient change (Daruwalla \& Darcy, 2005). Past studies have shown that less-educated employees show a greater discomfort in their interactions with people with disabilities (Gething, 1991).

\subsection{The Needs of Accessibility}

There are numerous obstacles to accessible accommodation noted in Darcy's study (2009): lack of accessible accommodation; accommodation that doesn't comply with access standards; importance of accommodation; level, 
detail, and accuracy of information; and locating accessible accommodation. Past studies have determined that demographic values, including income, gender, age, and marital status, are important indicators of accommodation choice. Two-thirds of respondents would travel more if they felt welcome at accommodations, and over $70 \%$ would travel more if they could locate accessible accommodation more easily. Noted in the study were seven factors that people with disabilities would change in the future: lower-friction surfaces, motorized drape pulls, wider hallways, multidirectional doors, light switches and phones placed closer to beds, and a reduction in the pieces of furniture (Darcy, 2009). In addition to these changes, people with disabilities also want accurate and detailed information about attractions. The ADA mandates that all business and services be accessible to persons with disabilities. If the recreation and tourism industry profession is to attain maximum business opportunities for all market segments, then the needs of visitors with disabilities must be a top priority (Chen, 2001).

\section{Purpose}

The purpose of the study was to identify the perceptions and attitudes of people with physical disabilities toward their experiences related to physical accessibility in the Great Smoky Mountains National Park, USA. This project aimed to (1) understand the experiences of visitors with disabilities with the accessibility of the park, (2) generate suggestions and recommendations from visitors with physical disabilities that would improve the level of accessibility in the park, (3) compile trip-related data (e.g., sources of information used, nights away from home, the benefits associated with a visit, etc.) from visitors with physical disabilities, and (4) provide information for greater understanding, planning, and maintenance in the park based on the needs of visitors with physical disabilities.

\subsection{The Background of the Great Smoky Mountains National Park}

The Great Smoky Mountains National Park encompasses 800 square miles. It is one of the largest protected areas in the eastern U.S. and receives millions of visitors each year. Although there are fluctuations in visitation from year to year because of many factors such as construction, bad weather, and economic recession, overall, the visitation series of the Great Smoky Mountains National Park reveals a mostly upward trend. The annual visitation of the Great Smoky Mountains National Park was estimated to exceed 5.9 million in 1969, 8 million in 1979, and 8.3 million in 1989. From the 1980s to 1990s, visitation rose 30 percent. Visitation exceeded 10 million in 2010 (National Park Service, 2011). As the Great Smoky Mountains National Park has become a more popular nature-based tourism destination, in order to provide better services and maintain visitor safety, it is critical to understand the needs of various national park users (Chen, 2001).

\section{Method}

The US National Center on Accessibility funded this project financially. The project director developed a survey instrument based on the input of the director of the National Center on Accessibility (NCA) and integrated it with the report outcomes of "Recommendations for Outdoor Developed Areas" published by the U.S. Architectural and Transportation Barriers Compliance Board. The study was conducted in the surrounding communities of the Great Smoky Mountains National Park, USA. The project staff recruited visitors with disabilities who are age 18 and older and use mobility devices (manual chair, power chair, cane, walker, scooter, and crutches) to participate in this study to provide their travel experiences in the national park.

Visitors with disabilities were asked to participate in the study by providing their names and addresses. Participants were then given a self-administered diary questionnaire and asked to fill out the survey onsite if they had finished their park visit or to mail it back in a postage-paid envelope at the end of their trip. A second copy of the questionnaire with postage-paid envelope was sent to those who had not responded within two weeks after the initial intercept. A total of 300 questionnaires were distributed to individuals with disabilities onsite. Of these questionnaires, 122 completed and usable questionnaires were collected. Data were gathered from the Great Smoky Mountains National Park visitors during the summer of 2001 and the summer of 2002. Returned surveys were coded and entered into a computer. Cross-tabulations and frequency distributions were calculated using a Statistical Analysis System (SAS) software package. Participants' comments from the open-ended responses were summarized. The results of this project provide useful information for park managers relevant to park accessibility.

\section{Results}

This study reported the demographic profiles of the visitors with disabilities including types of disabilities, age, gender, and the uses of various devices and assistance (e.g., wheelchair, walker, personal assistant, scooter, etc.). All of the participants had been to the park, and the mean number of trips to the park by these previous visitors was five times. The three most common devices used by visitors with disabilities (Table 1) were manual wheelchairs (61\%), power wheelchairs (37\%), and scooters (24\%). The visitors with physical disabilities also used walkers 
(19\%), personal assistants (13\%), and crutches (10\%). Of the study participants, visitors with physical disabilities ranged between the ages of 19 and 89 with a mean age of $47 ; 57 \%$ were female, and $43 \%$ were male (Table 2 ).

Table 1. Types of assistances/devices used by the visitors with disabilities

\begin{tabular}{lll}
\hline Assistances/Devices & Frequency & Percent $(\%)$ \\
\hline Hear Aids $(\mathrm{n}=122)$ & 6 & 5 \\
Walker $(\mathrm{n}=122)$ & 23 & 19 \\
Manual wheelchair $(\mathrm{n}=122)$ & 75 & 61 \\
Power wheelchair $(\mathrm{n}=122)$ & 45 & 37 \\
Personal assistant $(\mathrm{n}=122)$ & 16 & 13 \\
Crutch $(\mathrm{n}=122)$ & 12 & 10 \\
Scooter $(\mathrm{n}=122)$ & 29 & 24 \\
Service Animals $(\mathrm{n}=122)$ & 2 & 2 \\
Other device $(\mathrm{n}=122)$ & 4 & 3 \\
\hline
\end{tabular}

Table 2. Characteristics of visitors with disabilities

\begin{tabular}{ll}
\hline Characteristics & Visitors with physical disabilities \\
\hline $\mathrm{n}=122$ & \\
Age (average) & 47 \\
Gender & \\
Male & $43 \%$ \\
Female & $57 \%$ \\
\hline
\end{tabular}

Based on a seven-point scale (where $1=$ not a problem, $4=$ neutral, and $7=$ major problem), participants were asked to rate their experiences of accessibility during their visits to the Great Smoky Mountains National Park. Lack of knowledgeable and/or helpful park staff regarding accessibility in the park (3.8), and lack of accurate information on accessibility in the park (3.7) were rated by all participants. The physical accessibility problems rated by the visitors with physical disabilities $(n=122)$ were lack of the width of the doorways in restrooms $(4.6)$, lack of accessible trails (4.5), lack of grab bars in restrooms (4.4), lack of accessible restrooms (4.3), lack of appropriate urinal height in restrooms (4.3), lack of curb cuts (4.3), lack of accessible parking spaces (4.3), narrow tread width of outdoor recreation access routes (4.0), lack of accessible drinking water (3.9), lack of accessible overlooks and viewing areas (3.7), lack of accessible camping facilities (3.7), lack of accessible routes to the visitor center (3.5), lack of accessible storage facilities (3.5), lack of accessible utilities (3.4), and lack of accessible routes to trash/recycling containers (3.3).

Visitors with physical disabilities were asked to rate the levels of accessibility among various facilities (such as the picnic tables, grills, and fire rings). Particularly, we wanted to learn about the visitors' experiences and opinions towards 1) the height of the elements; 2) seating space provided; 3) knee space; 4) clear space surrounding the elements; 5) the ground surface; and 6) the ground slope. Lack of accessible route to the picnic table (4.2), lack of appropriate ground slope around the picnic table (4.1), lack of clear space for knees (4.1), and lack of appropriate ground surfaces around the table (4.1) were rated as a problem. Some visitors with physical disabilities indicated problems with the lack of appropriate ground slope around the grill (3.6), lack of clear floor or ground spaces around the grill (3.5), and the height of the grill (3.4). Lack of appropriate ground slope around the fire ring (3.6), the height of the fire ring (3.5), lack of appropriate ground surfaces around the fire rings (3.5), and lack of clear spaces around the fire ring (3.5) were also rated as problems.

Of 122 visitors with physical disabilities, 75\% indicated that "some" park parking lots provided accessible spaces; $10 \%$ indicated that "all" park parking lots provided accessible spaces; $4 \%$ indicated that "none" of park parking lots provided accessible spaces; $11 \%$ of respondents indicated that they did not know the answer. Forty-six percent of total respondents $(n=122)$ reported that information on park accessibility was readily available. Thirty-two percent of respondents indicated that they were offered the information on park accessibility without asking for it. For those who asked for information on park accessibility, the visitor center $(35 \%)$, internet $(15 \%)$, park ranger station $(14 \%)$, telephone call to the park $(6 \%)$, and disability resource center $(1 \%)$ were cited as the sources of information used (Table 3 ). 
Table 3. Sources of information on accessibility used by the visitors with disabilities $(n=120)$

\begin{tabular}{lll}
\hline Sources of information on accessibility & Frequency & Percent (\%) \\
\hline Internet & 18 & 15 \\
Park ranger station & 17 & 14 \\
Phone call to the park & 7 & 6 \\
Visitor center & 43 & 35 \\
Disability resource center & 1 & 1 \\
\hline
\end{tabular}

The overall satisfaction regarding the accessibility in the park was 4.5 (on a 1 to 7 scale), rated by all respondents $(n=122)$. Ninety-six percent of respondents indicated that they would come back to visit the park. The main reason given for a return visit was, "It's a beautiful park." The mean overall personal knowledge of federal accessibility laws and standards was 3.4 (on a 1 to 7 scale, $1=$ not at all knowledgeable, $4=$ neutral, and $7=$ very knowledgeable), rated by visitors with physical disabilities $(\mathrm{n}=122)$. Respondents were asked to identify three primary challenges encountered in making the park more accessible. The primary challenge identified was more accessible restrooms and trails. The second most common response was more funding for future development. The third challenge would be more accessible parking spaces and picnic areas.

\subsection{Travel Behaviors of Visitors with Disabilities}

The following section provides demographic profiles and trip characteristics (such as planning time, traveling distance, and lodging) of respondents. Thirty-two percent of respondents made their trip decision to visit the park less than one week in advance. This is followed by those indicating that the trip decision was made more than one week but within two weeks (20\%), more than two weeks but within one month (18\%), more than one month but within three months $(16 \%)$, on the day of the trip (11\%), and greater than three months (3\%) in advance (Table 4$)$.

Table 4. How far in advance the trip was planned? $(\mathrm{n}=122)$

\begin{tabular}{lll}
\hline Trip Planning Time & Frequency & Percent (\%) \\
\hline The same day & 14 & 11 \\
Less than one week & 39 & 32 \\
1 week but $<2$ weeks & 24 & 20 \\
2 weeks but $<1$ month & 22 & 18 \\
1 month but $<3$ months & 19 & 16 \\
$>3$ months & 4 & 3 \\
Total & $\underline{122}$ & $\underline{100}$ \\
\hline
\end{tabular}

Ten percent of respondents did not spend any night away from home. Of those visitors who did spend nights away from home, $25 \%$ spent one to two nights away from home, $44 \%$ spent three to four nights away from home, and $21 \%$ spent more than five nights away from home during their trip. Visitors were asked how far, in miles, they had traveled from their home origin to the Great Smoky Mountains National Park. Thirty-five percent of the visitors with disabilities traveled between 60 and 179 miles, followed closely by visitors traveling between 180 and 299 miles (24\%); 14\% traveled between 300 and 359 miles, $12 \%$ traveled less than 59 miles, $11 \%$ traveled between 360 and 599 miles, and $4 \%$ traveled above 600 miles (Table 5).

Table 5. Nights and miles

\begin{tabular}{llll}
\hline Trip Characteristic & Percent $(\%)$ & Trip Characteristic & Percent $(\%)$ \\
\hline Nights $(\mathrm{n}=122)$ & & Distance Traveled $(\mathrm{n}=80)$ & \\
0 night & 10 & $<59$ miles & 12 \\
1 night & 10 & $60-119$ miles & 16 \\
2 nights & 15 & $120-179$ miles & 19 \\
3 nights & 31 & $180-239$ miles & 15 \\
4 nights & 13 & $240-299$ miles & 9 \\
5 nights and above & 21 & $300-359$ miles & 14 \\
Total & $\underline{100}$ & $360-459$ miles & 6 \\
& & $460-599$ miles & 5 \\
& Above 600 miles & 4 \\
& Total & $\underline{100}$ \\
\hline
\end{tabular}


The previous experience (53\%), attraction brochures $(45 \%)$, and relatives $(41 \%)$ were the three most common sources of information used while planning trips. Friends were used as information sources by $36 \%$ of respondents. Other information sources were the internet (33\%), state highway maps (22\%), television (16\%), automobile clubs $(11 \%)$, and state tourism offices (11\%) (Table 6). About $49 \%$ of respondents indicated that they traveled with their family during the park visit, $37 \%$ indicated that they traveled with their family and friends, $5 \%$ indicated that they traveled with church groups, $2 \%$ indicated that they traveled with school groups, and $2 \%$ indicated that they visited the park alone (Table 7).

Table 6. Sources of information used for planning the trip

\begin{tabular}{lll}
\hline Sources of information on accessibility & Frequency & Percent $(\%)$ \\
\hline Automobile clubs $(\mathrm{n}=122)$ & 14 & 11 \\
Previous experience $(\mathrm{n}=122)$ & 65 & 53 \\
Attraction brochures $(\mathrm{n}=122)$ & 55 & 45 \\
Commercial guidebooks $(\mathrm{n}=137)$ & 20 & 16 \\
Relatives $(\mathrm{n}=122)$ & 50 & 41 \\
Friends $(\mathrm{n}=122)$ & 44 & 36 \\
Local tourist offices $(\mathrm{n}=122)$ & 12 & 10 \\
State tourism offices $(\mathrm{n}=122)$ & 14 & 11 \\
State highway maps $(\mathrm{n}=122)$ & 27 & 22 \\
Magazine ads/articles $(\mathrm{n}=122)$ & 11 & 9 \\
Newspaper ads/articles $(\mathrm{n}=122)$ & 8 & 7 \\
Radio $(\mathrm{n}=122)$ & 4 & 3 \\
Television $(\mathrm{n}=122)$ & 19 & 16 \\
Internet $(\mathrm{n}=122)$ & 40 & 33 \\
\hline
\end{tabular}

Table 7. Types of travel group $(\mathrm{n}=122)$

\begin{tabular}{lll}
\hline Types of Travel Group & Frequency & Percent (\%) \\
\hline Family & 60 & 49 \\
Friends & 7 & 6 \\
Family \& friends & 45 & 37 \\
Church groups & 6 & 5 \\
School groups & 2 & 2 \\
Visited alone & 2 & 2 \\
Total & $\underline{122}$ & 100 \\
\hline
\end{tabular}

Thirty-three percent of participants stayed in motels. Twenty-two percent of visitors with disabilities stayed in hotels, and 20\% stayed with friends and relatives (Table 8). Fourteen percent of participants indicated that they stayed in the park during their trip. Respondents indicated an average rating of 4.5 (on a 1 to 7 scale, $1=$ very dissatisfied, $4=$ neutral, 7 = very satisfied) for the effectiveness of the park's reservations system for camping and/or other lodging. The activities most frequently participated in by visitors with disabilities were having a picnic (71\%), visiting a scenic area (66\%), visiting a historical site (57\%), visiting a visitor center (53\%), visiting a museum (42\%), visiting the trails $(23 \%)$, camping (19\%), fishing (18\%), attending the amphitheater program $(16 \%)$, hiking $(12 \%)$, and boating $(5 \%)$ (Table 9$)$.

Table 8. Types of lodging $(n=116)$

\begin{tabular}{lll}
\hline Trip of Lodging & Frequency & Percent $(\%)$ \\
\hline Hotel & 26 & 22 \\
Motel & 38 & 33 \\
Campground & 9 & 8 \\
With friends/relatives & 23 & 20 \\
Resort & 4 & 3 \\
Bed \& breakfast/Inn & 4 & 3 \\
Cottage/cabin & 6 & 5 \\
Other & 6 & 6 \\
Total & $\underline{116}$ & $\underline{100}$ \\
\hline
\end{tabular}


Table 9. Activity engagement

\begin{tabular}{lll}
\hline Types of Activities & Frequency & Percent $(\%)$ \\
\hline Camping $(\mathrm{n}=122)$ & 23 & 19 \\
Visiting a historical site $(\mathrm{n}=122)$ & 70 & 57 \\
Visiting a scenic area $(\mathrm{n}=122)$ & 80 & 66 \\
Boating $(\mathrm{n}=122)$ & 6 & 5 \\
Having a picnic $(\mathrm{n}=122)$ & 87 & 71 \\
Hiking $(\mathrm{n}=122)$ & 15 & 12 \\
Attending the amphitheater program $(\mathrm{n}=122)$ & 19 & 16 \\
Fishing $(\mathrm{n}=122)$ & 22 & 18 \\
Visiting a museum $(\mathrm{n}=122)$ & 51 & 42 \\
Visiting trails $(\mathrm{n}=122)$ & 28 & 23 \\
Visiting a visitor center $(\mathrm{n}=122)$ & 65 & 53 \\
\hline
\end{tabular}

Thirty-nine percent of visitors with physical disabilities traveled from within Tennessee, $32 \%$ traveled from Georgia, 20\% traveled from North Carolina, 5\% traveled from Kentucky, and 2\% traveled from Virginia. Thirty-two percent of the respondents indicated that they have a high school diploma, followed by those indicating that they have some college (22\%). Of the remaining total respondents, $14 \%$ have two years of college, $11 \%$ have some graduate school, $8 \%$ have some high school, and $10 \%$ have less than a high school diploma (Table 10).

Table 10. Education level $(\mathrm{n}=122)$

\begin{tabular}{lll}
\hline Education & Frequency & Percent (\%) \\
\hline Grade school & 2 & 2 \\
Some high school & 10 & 8 \\
High school diploma & 39 & 32 \\
Some college & 27 & 22 \\
Two years college & 17 & 14 \\
Some graduate school & 14 & 11 \\
Master degree & 6 & 5 \\
Ph.D. degree & 7 & 6 \\
Total & $\underline{122}$ & $\underline{100}$ \\
\hline
\end{tabular}

The most common occupations of respondents were retired (29\%), homemaker (18\%), managerial/professional $(16 \%)$, and services support $(9 \%)$, while the most common occupations of respondents' spouses were retired (32\%), services support (25\%), and managerial/professional (21\%). Twenty-one percent of respondents indicated a household income of $\$ 20,000$ to $\$ 29,999,18 \%$ indicated a household income of $\$ 10,000$ to $\$ 19,999,16 \%$ indicated a household income of $\$ 30,000$ to $\$ 39,999,15 \%$ indicated a household income of $\$ 40,000$ to $\$ 49,999$, and $21 \%$ indicated a household income of above $\$ 50,000$ (Table 11). The benefits most important to visitors with disabilities were to relax (6.5 on a 1 to 7 scale), to observe the beauty of nature (6.4), to get some fresh air (6.3), and to increase fun/joy/enthusiasm (6.3). The least important benefits were to improve attitudes toward school (3.8) and to increase appropriate behaviors (4.3).

Table 11. Income $(\mathrm{n}=122)$

\begin{tabular}{lll}
\hline Income & Frequency & Percent $(\%)$ \\
\hline Under $\$ 10,000$ & 10 & 8 \\
$\$ 10,000-\$ 19,999$ & 22 & 18 \\
$\$ 20,000-\$ 29,999$ & 26 & 21 \\
$\$ 30,000-\$ 39,999$ & 20 & 16 \\
$\$ 40,000-\$ 49,999$ & 18 & 15 \\
$\$ 50,000-\$ 59,999$ & 8 & 7 \\
$\$ 60,000-\$ 69,999$ & 4 & 3 \\
$\$ 70,000-\$ 79,999$ & 6 & 5 \\
$\$ 80,000-\$ 99,999$ & 3 & 2 \\
$\$ 100,000$ or more & 5 & 4 \\
Total & $\underline{122}$ & $\underline{100}$ \\
\hline
\end{tabular}




\section{Discussion}

This study concludes that the motivations critical to visitors with physical disabilities are to relax, to observe the beauty of nature, and to increase fun/joy/enthusiasm. The activities most frequently participated in by visitors with disabilities were having a picnic, visiting a scenic area, and visiting a historical site. In order to sustain the travel business in the national park region, it is vital to understand what sources have been utilized by the visitors with disabilities. Visitors with physical disabilities are more likely to plan their trips to the Great Smoky Mountains National Park less than one week in advance, more likely to stay away from home during their trips, and more likely to use previous experiences, relatives, and attraction brochures for making their trip plans. These visitors with disabilities used various sources of information (e.g., attraction brochures, state highway maps, internet, and automobile clubs) for their trip plans; marketers of tourism organizations should provide these resources to visitors with disabilities. Marketers and products providers in the hospitality and tourism service sectors may consider adding more accessible information that would establish a positive image of attractions.

Since the Great Smoky Mountains National Park offers scenic and various outdoor recreational activities, relevant slogans could be established, such as, "The most accessible and hospitable National Park" and "Escape daily life to enjoy the freedom of natural scenes" to visitors with disabilities. The physical accessibility problems in the park identified by visitors with physical disabilities were lack of the width of doorways in restrooms, followed by lack of accessible trails, lack of grab bars in restrooms, and lack of curb cuts. In order to increase the satisfaction of visitors with disabilities and provide an optimal visitor experience, the sites with high attendance (e.g., visitor centers) may consider adding more accessible restrooms, or providing maps showing all the nearest facilities that are open for visitors with disabilities in the surrounding communities of the national park. The main challenge identified was more accessible restrooms and trails, more funding for future development, and more accessible parking spaces and picnic areas.

This study looks at the importance of accessibility in a national park and its impact on the ability of visitors with physical disabilities to experience a pleasant trip. For example, visitor centers are the primary liaison for people with disabilities to obtain the park's information once they are onsite. Most of the staff at the visitor centers in the park know the ins and outs of the attraction information and are trying to share their knowledge with visitors with disabilities. Being the most important first step in the travel experience, the effectiveness of visitor centers staff can result in a positive or negative travel experience for people with disabilities. Experienced staff in a national park can act as facilitators or barriers to the ultimate travel experience for people with disabilities.

Accessible tourism facilities that will accommodate the growing number of visitors with disabilities are expanding. In order to market these facilities, the information provided must be reliable. Including information on transportation and accommodation at attractions will be appealing to the visitors with disabilities. Also factoring in a reasonable budget is a must. This study concluded that visitors with disabilities and their families are a large and profitable population for the tourism and hospitality market. Not only do they travel, but they also spend money doing more planned activities as long as they are accessible. This is vital information for marketers to make their accessibility information easily available and clearer for visitors with disabilities. Additional research should be devoted to making these areas accessible under ADA standards and to meet the needs of specific disabilities. Marketers can also take advantage by training their employees on these differences.

As mentioned previously, the ADA (2000) brought change to the United States. However, the extra costs for people with disabilities to travel are not being addressed. Disability must be placed on the tourism policy agenda. Accurate access information needs to be provided. Most of the respondents stated that they would travel more if they could find adequate information on accessibility. These are policies that can easily be changed and positively impact the tourism market. For instance, there is a problem with tourists finding accessible accommodation information that is both accurate and detailed. Owners and managers often do not recognize the disability as a market and therefore do not promote the rooms or proper features of their facilities in the appropriate or marketable manner. Low occupancy in accessible rooms and customers without disabilities preferring regular rooms have placed providing large amounts of accommodation information at the bottom of the priority list. There is not enough research on attraction-related information, and visitors with disabilities are not the only people who want to have accessible information for their destinations.

The level of accuracy of accessibility information is important for tourists with disabilities to make decisions on travel arrangements. This information is critical for wheelchair users as it will allow them to know whether an attraction is wheelchair-accessible, for example. Other obstacles faced by visitors with disabilities are rarely noted in accessibility information and park visits: the height of the elements (such as the picnic tables, grills, and fire rings); seating space provided; knee space; clear space surrounding the element; the ground surface; and the 
ground slope.

Tourism is a right that all visitors with disabilities should be able to enjoy free from stress and worry. Legislation can help make landscapes and tourist attractions more accessible for visitors with various disabilities. And before that can happen, people must have a clear understanding of the effects that traveling has on visitors with disabilities. The world must view people with disabilities as part of the community in order for the research to impact the tourism sector. This study was meant to identify the difficulties faced by national park visitors with disabilities firsthand by allowing them to have a voice. This study urges future studies to look at specific disabilities. The travel experience had a major impact on whether visitors with disabilities viewed themselves as individuals with disabilities. The study suggests that park visitors should be treated differently with respect based on their specific impairments and not generalized based on physical features. Because of budget constraints, this study only investigated visitors with disabilities in the Great Smoky Mountains National Park, USA. In order to further understand accessibility in the US National Park Service, future research may consider collecting these patterns and attitudes from people with and without different disabilities (such as physical disabilities, hearing impairment, visual impairment) at various national park units (national parks, national historical sites, national parkways, and national monuments) at the state, regional, and national levels.

\section{Acknowledgments}

The author would like to thank the National Center on Accessibility and the Office of Research at the University of Tennessee for their financial support. I especially appreciate the help of the research assistants for achieving a very high quality sample.

\section{References}

Abeyratne, R. I. R. (1995). Proposals and guidelines for the carriage of elderly and disabled Persons by Air. Journal of Travel Research, 34(4), 52-59. http://dx.doi.org/10.1177/004728759503300310

Americans with Disabilities Act of 1990. (1990). U.S. Department of Justice, Civil Rights Division. Retrieved from http://www.usdoj.gov/crt/ada/pubs/ada.txt

Aronson, E., Wilson, T. D., \& Akert, R. M. (1998). Social psychology (3rd ed.). New York: Longman.

Baker, S. M., Stephens, D. L., \& Hill, R. P. (2002). How Can Retailers Enhance Accessibility: Giving Consumers with Visual Impairments a Voice in the Marketplace. Journal of Retailing and Consumer Services, 9, 227-39. http://dx.doi.org/10.1016/S0969-6989(01)00034-0

Bizjak, B., Knezevic, M., \& Cvetresnik, S. (2011). Attitude Change towards Guests with Disabilities: Reflections from Tourism Students. Annals of Tourism Research. http://dx.doi.org/10.1016/j.annals.2010.11.017

Brodia, J. K., \& Germann, C. (1999). Enhancing Accessibility Through Virtual Environments. Parks \& Recreation, 34(5), 94-97.

Burnett, J. J., \& Baker, H. B. (2001). Assessing the Travel-related Behaviors of the Mobility-Disabled Consumer. Journal of Travel Research, 40(1), 4-11. http://dx.doi.org/10.1177/004728750104000102

Chen, R. J. C. (2002). Visitor Expectations and Perceptions of Program and Physical Accessibility in the National Park Service. Bloomington: The National Center on Accessibility.

Chen, R. J. C. (2004). Uses of Hospitality and Leisure Services: Voices of Visitors with Disabilities. Advances in Hospitality and Leisure, 1(1), 89-102. http://dx.doi.org/10.1177/004728750104000102

Chou, S. H., \& Chao, W. C. (2007). Seeing Voices: Travel Experience and Individual Risk of the Hearing Impaired. In L. Andreu, J. Gnoth \& M. Kozak (Eds.), Proceedings of the 2007 Advanced in Tourism Marketing Conference (pp. 1-10). Valencia, Spain.

Darcy, S. (2010). Inherent Complexity: Disability, Accessible Tourism and Accommodation Information Preferences. Tourism Management, 31, 816-826. http://dx.doi.org/10.1016/j.tourman.2009.08.010

Daruwalla, P., \& Darcy, S. (2005). Personal and Societal Attitudes to Disability. Annals of Tourism Research, 32(3), 549-570. http://dx.doi.org/10.1016/j.annals.2004.10.008

Eichhorn, V., Miller, G., Michopoulou, E., \& Buhalis, D. (2008). Enabling Access to Tourism through Information Schemes? Annals of Tourism Research, 35(1), 189-210. http://dx.doi.org/10.1016/j.annals.2007.07.005

Fazio, R. H., \& Petty, R. E. (2008). Attitudes Their Structure, Function, and Consequences. New York: Psychology Press.

Fishbein, M. (2008). An Investigation of the Relationship between Beliefs about an Object and the Attitude toward 
that Object. In R. H. Fazio \& R. E. Petty (Eds.), Attitudes: Their Structure, Function and Consequences (pp. 137-143). New York: Psychology Press.

Gething, L. (1991). Interaction with Disabled Persons Scale: Manual and kit. University of Sydney.

Gröschl, S. (2007). An Exploration of HR Policies and Practices Affecting the Integration of Persons with Disabilities in the Hotel Industry in Major Canadian Tourism Destinations. Hospitality Management, 26, 666-86. http://dx.doi.org/10.1016/j.annals.2007.07.005

Huh, C., \& Singh, A. J. (2007). Families Traveling with a Disabled Member: Analyzing the Potential of an Emerging Niche Market. Tourism and Hospitality Research, 7(3/4), 212-29. http://dx.doi.org/10.1057/palgrave.thr.6050044

Israeli, A. A. (2002). A Preliminary Investigation of the Importance of Site Accessibility Factors for Disabled Tourists. Journal of Travel Research, 41(1), 101-4.

Jo, S., Huh, C., Kosciulek, J. F., \& Holecek, D. (2004). Comparison of Travel Patterns of Families with and without a Member with a Disability. The Journal of Rehabilitation, 40(4), 38-45.

Nicolle, C., \& Peters, B. (1999). Elderly and Disabled Travelers: Intelligent Transport Systems Designed for the 3rd Millennium. Transportation Human Factors, 1(2), 121-34. http://dx.doi.org/10.1207/sthf0102_1

Park, J. W. (2007). Passenger Perception of Service Quality: Korean and Australian Case Studies. Journal of Air Transport Management, 13, 238-42. http://dx.doi.org/10.1016/j.jairtraman.2007.04.002

Peniston, L. C. (1996). Hotel Accessibility and Accommodations for People with Disabilities. Parks \& Recreation, 31(12), 24-29.

Poria, Y., Reichel, A., \& Brandt, Y. (2010). The Flight Experiences of People with Disabilities: An Exploratory Study. Journal of Travel Research, 49(2), 216-227. http://dx.doi.org/10.1177/0047287509336477

Ray, N. M., \& Ryder, M. E. (2003). Ebilities' tourism: An exploratory discussion of the travel needs and motivations of the mobility-disabled. Tourism Management, 24, 57-72. http://dx.doi.org/10.1177/0047287509336477

Shaw, G. (2007). Disability Legislation and Empowerment of Tourists with Disabilities in the United Kingdom. In A. Church \& T. Coles (Eds.), Tourism, Power and Space (pp. 83-100). London: Routledge.

Shaw, G., \& Coles, T. (2004). Disability, Holiday Making and the Tourism Industry in the UK: A Preliminary Survey. Tourism Management, 25, 397-404. http://dx.doi.org/10.1016/S0261-5177(03)00139-0

Shaw, G., Veitch, C., \& Coles, T.E. (2005). Access, Disability and Tourism Changing Responses in the United Kingdom. Tourism Review International, 8(3), 167-76. http://dx.doi.org/10.3727/154427205774791555

Travel Daily News. (2003, January 22 ). Travelers with disabilities could spend $\$ 27$ billion per year. Retrieved from http://www.traveldailynews.com/ new.asp?newid=10027 \& subcategory_id=83

Turco, D. M., Stumbo, N., \& Garncarz, J. (1998). Tourism Constraints for People with Disabilities. Parks and Recreation, 33(9), 78-85.

World Health Organization. (2011). Disability, Including Prevention, Management and Rehabilitation. Retrieved from http://www.who.int/nmh/a5817/en/

Yates, K. (2007). Understanding the Experience of Mobility-Disabled Tourists. International Journal of Tourism Policy, 1(2), 153-66. http://dx.doi.org/10.1504/IJTP.2007.015525

Zanna, M. P., \& Rempel, J. K. (2008). Attitudes: A New Look at an old Concept. In R. H. Fazio \& R. E. Petty (Eds.), Attitudes: Their Structure, Function, and Consequences (pp. 7-17). New York: Psychology Press. 